\title{
Matt Morgan: Those three little words
}

\author{
Matt Morgan intensive care consultant \\ University Hospital of Wales
}

I still remember the first time I said those three little words. Growing up in a loving Welsh family, I'd heard them said many times. But the first time they roll off your tongue will always be different. You try to choose your moment, but sometimes the words take you, and the listener, by surprise.

If "I love you" are the three most important words in life, then "I don't know" are the three most important in medicine. They're also the most underused. Their power comes from admitting that doctors don't, and can't, know everything.

For me, the first time I admitted to a patient's family that I didn't know the answer was after caring for a young man who died from sepsis. I was a doctor on the intensive care unit, surrounded by fancy blood tests and scans. Yet I couldn't answer his family's most basic, most important question. Trying to comprehend what had just happened, his mum asked, "Why him? Why has he died?"

All medical encounters revolve around things we don't know. Patients and families often challenge us to predict the future, asking, "Will she survive?" or, "When can I go home?" Like the best meteorologists we must integrate science, history, and our gut instinct to make a stab at an elusive possibility that we hope clings to a truth.

Consider a weather forecast of a $90 \%$ chance of rain. If the sky stays blue the prediction wasn't wrong-truth just happened to be found in that smaller $10 \%$. Openness about uncertainty can lead to more understanding: a 90\% chance of rain may tell you to take an umbrella, but "I don't know" is the start of longer, more nuanced conversations.

Looking a patient or relative in the eye while saying "I don't know" is hard. They're difficult words to say. It's hard to admit the limits of our knowledge, and sometimes it means hinting at the boundaries of medical understanding. Patients and families often expect doctors to have solid answers, or they assume that modern medicine can cure them. It can come as a surprise when we don't and can't.

They're also risky words. When you're standing on the solid ice of reason it can easily get slippery when that ice begins to melt. You can fall, become unsteady, and have little to grip on to. It's a disorientating and unnerving experience for doctors to say, "I don't know," and once you admit the limits of your knowledge it can make you question more and more.

Yet these words also carry immense power: the power of hope, because there may be that chance to recover. They also carry the power to inspire people to strive for a better understanding of what's not yet known. Even when these things don't follow and hope is lost, perhaps honesty with yourself and those you care for is good in itself-although I'm not sure about that either. I don't know.

Competing interests: I have read and understood BMJ policy on declaration of interests and declare that I have no competing interests.

Provenance and peer review: Commissioned; not externally peer reviewed.

Matt Morgan is an honorary senior research fellow at Cardiff University, consultant in intensive care medicine and research and development lead in critical care at University Hospital of Wales, and an editor of BMJ OnExamination. His first book, Critical, was published in 2019.

Published by the BMJ Publishing Group Limited. For permission to use (where not already granted under a licence) please go to http://group.bmj.com/group/rights-licensing/ permissions 